gleich erachtet. Auf Wunsch habe ich nach derselben Methode Stifte aus Alaun und solche aus einem Gemisch von Alaun und Kupfersulfat etc. von ausgezeichneter Haltbarkeit und zweckentsprechend dargestellt.

Nach wenigen Versuchen ist es, wie gesagt, keine Schwierigkeit, den richtigen Grad der zähen Consistenz der noch warmen Masse zu erreichen, welche nach dem Ausrollen und Erkalten einen festen Aetzstift giebt, und wird der Krystallwasserverlust, welcher sich beim Gebrauche an der Wundfläche auch wieder ersetzt, die Wirksamkeit wohl nicht vermindern.

\title{
Borsäure als Mittel gegen das Säuern der Milch.
}

Von A. Hirschberg. - Sondershausen.

Im Aprilheft des Archirs der Pharmacie vom Jahre 1872 werden die Versuche veröffentlicht, welche ich damals nach dieser Richtung hin angestellt hatte und ist dieser Aufsatz s. Z. auch in die "Milchzeitung “ übergegangen. In No. 17 dieser Ztg. vom 4. Febr. 1874 berichtet Dr. L. Wittmack in Berlin über Versuche, welche nach den Annali di Chimia etc. Professor Polli auf Grund meines Aufsatzes über die antiseptische Wirkung der Borsäure angestellt hat.

Von frischgemolkener Kuhmilch wurden $400 \mathrm{~g}$. in 8 Gläser vertheilt und der Luft ausgesetzt, bei einer Temperatur von 15 bis $18^{\circ} \mathrm{C}$. stehen gelassen. Eins dieser Gläser erhielt lseinen Zusatz; die Milch in demselben war schon am folgenden Tage ein wenig, nach 5 Tagen aber ganz sauer, wobei die Milch zu einer zusammengeballten, mit einer sauren Rahmhaut bedeckten Masse geronnen war.

Die anderen sieben Gläser zu $50 \mathrm{~g}$. enthielten jedes einen anderen Zusatz und zwar je $1 \mathrm{~g}$. bez. Borax, Borsäure, schwefelsaures und unterschwefligsaures Natron. Jede Stunde wurde die Flüssigkeit ein wenig geschüttelt.

Nach fünf Tagen hatte sich auf der mit schwefelsaurem Natron versetzten Milch eine Schicht gebildet, bald darauf 
auch auf der mit unterschwefligsaurem Natron behandelten. Die Milch war molkig geworden, reagirte sauer und hatte einen Geruch nach schwefliger Säure. Die mit Borax und mit Borsäure versetzten Proben dagegen waren vgleichförmig geblieben. Ihr Geruch war der der gewöhnlichen Milch, nicht sauer, und unter der gebildeten leichten Haut hatte sich kein Serum abgeschieden. Die Prüfung mit Lackmuspapier ergab bei Borax eine alkalische, bei Borsäure eine saure Reaktion. In dem Gefässe ohne Zusatz war um diese Zeit die Bildung von Milch - und Buttersäure dentlich bemerkbar.

Die mit Borax und noch mehr die mit Borsäure versetzten Proben zeigten auch nach 20 Tagen nur eine leichte Haut auf der Oberfläche, aber keine Gerinnung; auch hatten sie noch den reinen Geschmack der frischen Milch, während in dieser Zeit die beiden anderen mit Natronsalz versetzten Proben coagulirt waren, einen Geruch nach Milchund Buttersäure besassen und sich mit einer klumpigen Haut voll kleiner knotiger Erhabenheiten bedeckt hatten, auf denen grüne und einfarbene schimmelpilze vegetirten.

So weit Dr. Wittmack, und constatirt derselbe, dass gegenuiber den giftigen Eigenschaften anderer antiseptischer Mittel die Borsäure in kleinen Mengen der Gesundbeit durchaus nicht nachtheilig ist und dabei cinen sehr milden Geschmack hat. Die Grösse der als Zusatz zur Milch anzuwendenden Menge sei genauer wohl noch nicht erforscht. -

$\mathrm{Zu}$ den von mir im Juni 1871 veranlassten Versuchen wurde auf zwei Pfund frischer Nilch $1 \mathrm{~g}$. Borsäure verwendet, und mit dieser Menge, welche nur $1 / 20$ der von Professor Polli verwendeten ausmacht, insofern noch günstigere Resultate erlangt, als bei meinen Versuchen die Milch sich in $\mathrm{flachen}$ Gefässen, demnach in der Einwirkung der Luft noch mehr exponirten Vorhältnissen befand. Wenn nun auch der Borax ähnliche antiseptische Wirkungen besitzt, so ist doch die Borsiiure demselben um deswillen vorznzichen, weil der Borax, gleich wie das zur Entsänerung der Milch oft angewandte doppelt kohlensaure Natron die Milch bald schwachgclblich färbt, und derselben einen leisen seifenartigen Ge- 
schmack verleiht. Das von Trommer zur Entsäucrung der Ililch rorgeschlagene kaustiche Ammoniak hat diese Eigenschaften nicht.

Beilüufig sei hier erwähnt, dass ein geringer Zusatz von Borax der Unbequemlichkeit abhilft, welche sich beim Buttern zuweilen dahin zeigt, dass die Butterkügelchen sich nicht vereinigen oder, wic man es nennt, nicht zusammgehen wollen.

Die praktische Bedeutung der hior bchandelten Eigenschaft der Borsüure liegt zu Tage, beispielsweise mag angofuhrt werden, dass dem Berichte des Chefs des Nordamerikanischen Ackerbaudepartements für das Jahr 1871 zufolge u. A. die Stadt Newyork schon damals zum Theil aus einer Entfernung von 225 engl. Meilen täglich per Bahn mit frischer Milch versorgt wurde und dass nit dem Anwachsen der Einwohnerzahl der tägliche Milchbedarf dieser wie anderer grossen Städte der nordamerikanischen Union aus noch grüsseren Entfernungen wird gedeckt werden müssen.

Aus den von Dr. Wiltmack gegebenen historischen Nachweisen ist anzufithren, dass Hoppe und Alex. Müller die Milch conservirenden Eigenschaften von S̈̈uren im Allgemeinen bereits längst verstehen gelehrt haben. Neuerdings hat I) umas, welcher sich mit der Entstehung der Borsäure in den Fumarolen von Tuskana Leschiatiggie, ebenfalls die conservirende Eigenschaf der Borsäure studirt. Carlo Pavesi bestätigt dessen Angaben mit dem Hinzufügen, dass die Borsäuro die kntwitkelıng ron Ozon veranlasse.

Hinzuzulügen ist, dass nach Compt. rendus, Chem. Centralblatt 1872 S. 567, Du mas ermittelt hat, dass Borsäure Bierhefe, Synaptis, Diastas und Myrosiu unwirksam macht. A. Rabuteau und F. Papillon a. a. O. S. 792 haben gefunden, dass Natronsilicat die Zersetzung von Must, Harn, Milch, die einer Eumlsion ron süssen und von bittern Mandeln, und von Galle, Eitor und Eiweiss total, die Zersetzung von Blut und die Gährung des Traubenzuckers nur temporär verhindere. 